Running head: FEMALE TERRORISM RESEARCH

\author{
Female Terrorism: A Review \\ Submitted: March 1, 2008
}

\author{
Karen Jacques and Paul J. Taylor \\ Lancaster University, UK
}

\begin{abstract}
Authors Note
Karen Jacques, Department of Psychology, Lancaster University , Lancaster, UK; Paul J. Taylor, Department of Psychology, Lancaster University, Lancaster, UK.

This research is based on work towards the first author's Ph.D. thesis, supervised by the second author and funded by a UK Economic and Social Research Council studentship (PTA-030-2006-00351).

Correspondence should be addressed to Karen Jacques, Department of Psychology, Lancaster University, Lancaster, UK, LA1 4YF. Tel: +44 (0) 1524 594421; E-mail: k.jacques@lancaster.ac.uk
\end{abstract}

Keywords: female terrorism, radicalization, motivations, recruitment, metaanalysis, review

Karen Jacques (MSc, Liverpool) is a second-year PhD student at Lancaster University where she is researching the psychology of female involvement in extremism. (see http://www.psych.lancs.ac.uk/people/KarenJacques.html)

Paul J. Taylor (PhD, Liverpool) is Senior Lecturer in Forensic Psychology at Lancaster University where he directs the Department's MSc in Investigative Expertise (see http://www.lancs.ac.uk/staff/taylorpj/LISN/index.htm). 


\begin{abstract}
The sharp growth in the number of publications examining female involvement in terrorism has produced a valuable but un-integrated body of knowledge spread across many disciplines. In this paper, we bring together 51 publications on female terrorism and use qualitative and quantitative analyses to examine the range of theoretical and methodological approaches in these papers. Using thematic analysis, we identify six primary research foci: Portrayal in media, Feminism, Interviews with terrorists, Group roles, Motivation and recruitment, and Environmental enablers. Analyses also revealed a reliance on secondary rather than primary data, narrative rather than statistical comparisons, and descriptions rather than explanations of events.
\end{abstract}




\section{Female Terrorism: A Review}

In 1983, the Argentinean sociologist Georges-Abeyie noted that women have traditionally played a minor role in terrorist violence, but that an increase in female participation could be expected in the future ${ }^{1}$. His prediction appears to have been accurate, with female involvement in terrorism now widely acknowledged as having increased "regionally, logistically and ideologically",2. As female involvement in terrorism has increased so too has female terrorism research, reflected by the increase in the number of related publications and special issues dedicated to the subject ${ }^{3}$. These articles investigate a wide range of issues, and they appear across a diverse range of publications that encompass disciplines such as politics, women studies, psychology, and anthropology.

Given the burgeoning of work in this area, it seems timely to draw together and critically assess the literature that has been published to date. We undertake such a review in this paper, which we organise around several related objectives. First, our review seeks to map out the nature of current knowledge on female terrorism. We capture the developing trends in understanding, identify where theories are gaining wider support, and highlight areas in which particular methodologies have proven fruitful. Equally, we bring to light some of the untested assumptions of the field, highlight areas where the field has not made progress, and provide an assessment of the adequacy of the methodological techniques and analytical methods that are currently being employed.

Second, our review provides new frameworks for conceptualising salient aspects of female terrorism. Specifically, by drawing together the published literature our review identifies trends and common features that are not forthcoming from findings drawn in a single case study. These trends and commonalities have a degree 
of reliability and generalizability that should help to build cumulative knowledge in the field. As Hammersley notes ${ }^{4}$, when dealing with qualitative research, the synthesis of evidence can allow the construction of longer narratives and more general theories ${ }^{5}$. These resulting narratives then provide a marker that researchers may use in the future to assess progress in the field.

\section{Background to Terrorism Research}

Studies into terrorism have traditionally focused on men, arguably due to the longstanding belief that women have assumed passive, inherently less interesting roles in extremist groups ${ }^{6}$. However, more recently, researchers have highlighted the influential roles that women have held in organisations over the last few decades ${ }^{7}$. These researchers argue that deriving a coherent account of the circumstances behind female involvement in terrorism is essential to any comprehensive understanding of the phenomenon and that, consequently, it is likely to play an important role in the development of counter-terrorism strategies.

To date, research on female terrorism has considered a myriad of different issues and, arguably, there has been no clear progression from early work to where the field stands today. Research produced in the 1970s and 1980s focused on topics such as female involvement in the Russian revolution ${ }^{8}$, females fighting in the guerrilla wars of Latin America ${ }^{9}$ and the psychological reasons that underlie female involvement in extremism ${ }^{10}$. The 1990 s saw a continuation of the earlier focus on Latin America, but this was accompanied by a growth in research on Irish terrorists and terrorism. The 1990s also saw the publication of the only two books of the decade to present detailed case studies of female terrorists ${ }^{11}$. However, while publications on female terrorism increased after the year 2000, the range of foci and disparate events covered within the literature suggests an absence of both strong theory and testing of 
that theory. For example, between the years 2000 and 2001, research on female terrorism encompassed the psychology of female involvement ${ }^{12}$, an overview of female involvement in suicide terrorism ${ }^{13}$, and a publication detailing representations of female terrorists ${ }^{14}$. None of these themes were continued in research published in 2003. This lack of cumulative development echoes the trends in general terrorism research found by Silke ${ }^{15}$.

Since the 1990s, research into female terrorism has continued to develop across a number of disciplines. For example, studies in psychology have examined issues such as motivation, female identity, and radicalisation ${ }^{16}$, as well as issues of individual difference such as the psychological underpinnings of suicide terrorism ${ }^{17}$. Studies by sociologists have also made significant contributions, exploring the impact of factors that include religion ${ }^{18}$, societal influences ${ }^{19}$ and gender ${ }^{20}$. Other research includes a discussion of what criminology could bring to research on female terrorism $^{21}$, work on the different portrayals of female suicide bombers in Eastern and Western media $^{22}$, feminism and feminist theories of female terrorism ${ }^{23}$, women and female involvement in organised racial terrorism ${ }^{24}$, and female involvement in the Russian subculture ${ }^{25}$.

The consequence of this broad range of foci is the juxtaposition of competing hypotheses, with no comparison across and between the findings presented in different publications. For example, the account by Victor argues that women are drawn reluctantly into terrorism and are motivated by personal, private reasons. In contrast, Cunningham argues that women hold more complex, dualistic reasons for their involvement, combining collective motivations, such as a desire for national independence, with individualistic motivations, such as the desire for equality between the sexes ${ }^{26}$. Such conflicting accounts mean that efforts to develop a detailed 
picture of female involvement have yet to provide a definitive narrative of underlying factors. Thus, there is a danger of research into female terrorism becoming "bogged down in a conceptual mire" in a way similar to what Silke identified in general terrorism research ${ }^{27}$. Thus, the drawing together of research on female terrorism is an important step in avoiding this conceptual mire.

In the remainder of this paper, we describe our analysis of publications on female terrorism. We begin by outlining our method of collating together the publications, including how we identified the research and the inclusion criteria for publications to be reviewed. We then describe our approach to analysing their theoretical and analytical content. This analysis focuses on two aspects of published research. First, we focus on how the research was conducted, including the type of data used and the analytical techniques employed to assess the quality of the data, test hypotheses, and evaluate the reliability of derived results. Second, we examine the topic of focus in the papers, and bring together some of the knowledge generated in the research. This will distinguish areas of agreement and disagreement among researchers, along with gaps in understanding.

\section{Research on Female Terrorism}

\section{Literature Search}

Due to the diverse nature of research into female terrorism, articles were collated from a number of sources. First, we searched well-known bibliographic databases in the areas of psychology, sociology and political science. Specifically, the databases APA PsycInfo, Socio Abstracts, Medline, ASSIA (Applied Social Sciences Index and Abstracts) and Web of Knowledge, were each searched using the reference words "female", “woman”, “terrorist”, "terrorism”, “martyr”, "suicide bomber”, "guerrilla" and "revolutionary". Second, the Reference, Footnote, and Bibliography 
sections of the resulting articles were examined for as yet un-captured research papers, and this process repeated on any new papers until no new references of relevance appeared in the References or Bibliographies. Third, internet searches were conducted by inputting the above reference terms into a popular worldwide search engine and its scholarly literature search engine.

The publications identified through the database and internet searches were included in our review if (and only if) they focused on issues relating to female terrorism, or if they dedicated a section of their analysis to female terrorism. Publications included in the review was limited to books, articles published in peer reviewed journals, conference reports and proceedings, $\mathrm{PhD}$ theses, and reports published by leading counter-terrorism centres. Newspaper articles, films, and dissertations submitted as part of a Masters degree were not included. Moreover, to ensure the review is relevant to female terrorism research today, the review is limited to research published within the past 25 years. By using this set of criteria, we sought to ensure that our review included peer-reviewed academic work, rather than media reporting or personal opinion.

\section{Analysis of Publication Content}

There are a number of methods available for drawing together diverse material and "painting a picture" of what researchers know about a particular issue. These different methods are often collectively referred to as meta-analysis techniques. When the purpose of the analysis is to draw together quantitative studies, then there are a number of statistical techniques available for comparing numerical findings ${ }^{28}$. When the purpose is to draw together the results of qualitative studies, then there are a number of different techniques for identifying trends and commonalities in the data. In their recent review, Dixon-Woods and his colleagues distinguished nine different 
meta-analytical approaches to qualitative evidence, which ranged from thematic analysis to cross-case data analysis ${ }^{29}$. For example, one of the techniques they identify — thematic analysis — involves identifying prominent or recurrent themes in the publications, which are summarized under thematic headings in tables or key points $^{30}$. In contrast, cross-case data analysis takes a more rigorous approach ${ }^{31}$ where information is portioned and clustered into cells within a meta-table or matrix. The resulting cells then form the basis of cross-case comparison and analysis.

Compared to their quantitative counterparts, methodologies for qualitative meta-analysis are still in their infancy. As such, there is no consensus in the academic literature as to a preferred or superior approach. Nonetheless, this meta-analysis of qualitative data, independent of specific technique, has enabled the enhancement of findings by formalizing knowledge in a way that is meaningful and useful to the discipline $^{32}$. Specifically, qualitative meta-analyses have been used effectively in a number of diverse areas such as supply chain performance ${ }^{33}$, community action projects ${ }^{34}$ medical case studies such as depression, HIV and diabetes ${ }^{35}$, and domestic violence $^{36}$. Each study has contributed significantly to its field by combining existing information optimally to identify trends, patterns, problems and future directions.

\section{Results}

Our database and internet searches resulted in a collection of 54 publications on female terrorism, which included 6 books, 3 book chapters, 29 journal articles, 1 doctoral thesis and 15 reports. This material is marked in the Reference section using $a^{\text {‘*' }}$. Figure 1 presents the number of publications in our sample as a function of the year of publication (some years are grouped together due to the infrequency of publications during a year). Of the total collection, 38 publications (70\%) appeared after the year 2002, which represents nearly a three-fold increase in the number of 
publications relating to female terrorism. Prior to 2002, publications on female terrorism were published approximately once to twice every two years. There were eight publications on female terrorism produced in 2003, which co-occurs with the first reporting of women as suicide bombers in the second Palestinian intifada. A similar number (seven) were produced in 2004. There was another increase in 2005 where 11 publications were published, which coincides with female involvement in the Dubrovka theatre siege. This increase was maintained in 2006 with 12 publications, possibly due to female involvement in conflict in Iraq. Use of Research Methodology

Data source. As a first step to uncovering the nature of female terrorism research, we considered the extent to which researchers have drawn on first and second hand data in their papers, and also the extent to which they cite academic or media reports to support their arguments. In total, 42 of the 54 published articles (78\%) relied on secondary data such as published articles or media reports. The remaining 12 articles (23\%) had undertaken primary research using interviews or questionnaires. The number of interviewees on which studies were based has ranged from 1 to 205 (on which a book was based), with a median of 11.5 interviews.

In terms of citations, an analysis of the bibliography sections of papers found that researchers had cited academic articles slightly more frequently than media reports, with a ratio of approximately four media reports being cited to every five articles. However, this ratio has shifted over time with more academic research and less media reporting becoming the norm in published articles. For example, the ratio of media-academic sources cited in articles published prior to 2002 was approximately $1: 1$. This changed to a ratio of nearly $3: 4$ for articles published after 2002. 
These figures show a reliance on secondary data, with most researchers not producing substantively new data or knowledge, but reworking old material to support a particular argument or to exemplify a particular analytical framework. This finding parallels Silke $\mathrm{s}^{37}$, who found that over $80 \%$ of his sample of terrorism research was based either solely or primarily on pre-existing data. It also reflects a decrease in primary data gathering from $46 \%$ as reported in 1988 for general terrorism research ${ }^{38}$ to $23 \%$.

Method of analysis. As Figure 2 shows, numerical analyses are infrequently employed in research on female terrorism. Consistent with Silke's previous reporting of infrequent use of statistics in terrorism research ${ }^{39}$, we found that 33 of the 54 studies in our sample (61\%) include no numerical analysis of any kind. Of the 21 studies that did report analyses, 15 (28\%) used frequency-based descriptive statistics to show either the proportion of women found within specific terrorist groups, or the proportion of women who have carried out terrorist acts relative to men. A further five articles (9\%) used descriptive statistics to represent demographic information about the age, marital status and socio-economic status of the females involved in extremism. Only one paper deployed inferential statistics. This paper coded terrorist events and terrorist profiles and subjected this data to a multivariate analysis in order to ascertain altruistic or egotistic aspects of suicide terrorism ${ }^{40}$.

\section{Conceptual Focus of Research}

To uncover more about the character of research into female terrorism, the 54 articles were examined to determine their main conceptual focus. This was achieved in two stages. First, to identify the major areas in which work has been conducted, we undertook a thematic analysis of each article. Thematic analysis involves identifying recurrent issues or points in the text being examined, where these issues can be 
grouped under a general heading or theme that is important to a description of the phenomenon $^{41}$ (e.g., feminism, environmental enablers). These themes were identified using an iterative process of reading and categorisation, with the emerging themes becoming the primary foci for analysis ${ }^{42}$.

Second, in order to extract detailed information, the primary foci were examined using the "constant comparative" method ${ }^{43}$; which utilises a grounded theory approach. Concepts across studies were identified and clustered into new categories by the first author. Using a process of iterative refinement, the categories were refined until they clearly reflected the relevant information in the articles. The data were exhaustively re-analyzed and categories added and removed until all informative concepts were appropriately assigned a category. For example, within the environmental enablers category a wide number of factors were identified that impacted upon female involvement in terrorism. These were then grouped into four larger categories of strategy, internal strategy, social and advantages (see below).

Overall, six primary foci were identified, namely: History and overview of female terrorism; Perceptions of female terrorists (media); Roles of female terrorists; Motivation and recruitment (both motivation and recruitment found within case study materials); Environmental enablers, and; Other. The number of articles identified as adopting one of these six as its primary focus is shown in Table 1. To provide a more detailed analysis of the research (recognising that many studies consider multiple issues), Table 1 also identifies the secondary focus of articles. An article's secondary focus was identified as the issue that was explored in most detail after the primary focus, where failing to mention the second focus would have left theories or argument in the paper incomplete. The distinction between primary and secondary foci was 
determined by amount of coverage given to each issue. ${ }^{44}$ We examine each of these foci in the next sections.

\section{Historical Accounts and Overviews}

As shown in Table 1, 22 of the 54 articles (41\%) were found to provide generic overviews of female involvement in terrorism or descriptions of the history of female involvement in specific conflicts. Of these articles, 9 provided overviews of female involvement, 10 described female involvement in specific conflicts, and 5 were best characterised as intersecting both of these areas. Within these publications, authors introduce the topic of female terrorism as a research area. This can encompass detailing the origins of terrorism, defining the word 'terrorism', and providing examples or case studies of early female involvement in terrorism. The history of a specific conflict may also be given, describing causes of the conflict and how female participation started or evolved. These papers focus on recounting existing knowledge rather than conducting primary research or evaluating existing research.

\section{Perceptions}

Studies examining perceptions of female terrorists generally explore the notion that we find it difficult to comprehend female involvement in terrorism and that we deal with this by representing female terrorists in one of two ways. We either resort to mythical stereotypes ${ }^{45}$ or we resort to gendered stereotypes ${ }^{46}$. According to Berkowitz, mythical stereotypes portray female terrorists as women warriors beautiful, sexy, smart, tough and deadly ${ }^{47}$. This portrayal serves two functions. First, it helps convey news in a package with which the audience is familiar. The public are accustomed to depictions of sexy, smart and deadly women warriors and thus the female terrorist is rendered culturally intelligible ${ }^{48}$. Second, it serves to hide the 
individual activist so that we do not have to struggle to understand her as an individual.

In contrast to the focus on mythical stereotypes, Patkin suggests that we seek alternate explanations for female terrorism that draw on issues of gender to minimise the female role. She suggests that this occurs either through explanations of involvement that draw on traditional gender roles, or through a "feminising" of motivations that involves representing females' motivations as more personal and individual than perhaps they need to be ${ }^{49}$. The social background and family history of the female, along with her love interests (if any), are raised as possible alternative motivations, thereby providing a gendered interpretation of events ${ }^{50}$.

The reviewed articles argued that if these alternative explanations are not available, then the female terrorist is either portrayed as unnatural, unfeminine and unsexed, or as an "irrational terrorist personality". The result is a dichotomy of perception in the media- either as an irrational woman or a terrorist who is more man than woman ${ }^{51}$. Both of these portrayals and the resulting dichotomy minimise the perceived threat posed by female terrorists, whether or not this is the intention of the papers' presentation. Talbot reports that this dichotomy or paradox of the female terrorist can work to the advantage of the terrorist group, who may exploit cultural gender clichés employed by the media to their tactical advantage ${ }^{52}$.

One important feature of the perceptions research discussed so far is that it reports media representations from a Western societal perspective. However, studies have shown that there are significant differences between the portrayal of female terrorists in the Western and Arab media ${ }^{53}$. Issacharoff, in particular, found that the Western media focuses on personal aspects of the female terrorists, such as biographical details, social circumstances, and the constraining influence of a 
chauvinistic society ${ }^{54}$. In this Western focus, behaviour is accorded to external factors and not personal motivation, with action attributed to factors over which the female has no power. This portrayal diminishes personal influence and the credibility of women as terrorists. However, the Arab press is freer of gender stereotypes and downplays any individual problems of female terrorists not related to the ideology of the struggle. It develops the feminist dimension by portraying female terrorists as full partners in the struggle, emphasising their religious and/or nationalistic motivations in much the same way as the Western media does for male terrorists. In this way, they are portrayed as equal to men, as fighters.

\section{Feminism and Gender Studies}

Analysis of the six articles primarily focusing on feminism and gender suggests that this literature divides into those that use the female terrorism literature to advance feminist theory and those that use feminism to advance the female terrorist argument. These two approaches offer different perspectives, with the former examining female terrorism as an instance of a patriarchal world and the latter arguing that females play active roles in the extremist groups of which they are a part. Those that use the female terrorism literature to advance feminist theory argue that women are oppressed and manipulated by men to become terrorists, ${ }^{55}$ and that terrorism is the result of a patriarchal world ${ }^{56}$. For example, Berko and Erez in their 2006 report state that Palestinian women in terrorism are an aspect of systematic gender oppression and that female Palestinian terrorists are mere tools of male Palestinian society. By arguing that women are disadvantaged in a patriarchal world, these studies minimise women's agency in terrorist acts.

This contrasts the work of other authors, such as Alison, Gentry and West, who demonstrate that analyzing female terrorism through a feminist lens can 
contribute to our understanding of the field ${ }^{57}$. By interviewing female terrorists and concentrating on women, especially women as agents, the perspectives of the female as disadvantaged and passive are dismantled and the contribution of women to terrorism brought to the fore. For example, female terrorists are often taken out of context $^{58}$ and assumed to be more peaceful and less aggressive than men ${ }^{59}$. Yet, by examining first-hand accounts of female terrorists, the acts that they have perpetrated and the motivations behind these actions, researchers have shown that women are active agents that often play important roles in the extremist group. McDonald, in particular, interviewed a number of terrorists who participated in different conflicts. A reoccurring theme in this research (with the exception of Kim Hyon Hui) was the willingness of women to participate in the actions of the group, as well as take an active role in the decision making processes of the group ${ }^{60}$.

\section{Motivation}

Case studies are an ideal way to illustrate an argument and they are used frequently throughout the female terrorism literature, often to detail motivations for terrorist activity. Table 2 outlines the five main forms of motivation that we identified as being discussed in the 54 publications. These are Social, Personal, Idealistic, Key Event and Revenge motivations. Of all the motivations that emerged, Social motivations were discussed significantly more than others with 34 mentions (All $\chi^{2}>$ $4.92, \mathrm{df}=1, \mathrm{p}<.05)$, cited a total of 34 times. Social motivations are frequently noted in publications examining conflicts in Latin America where better living conditions are one of the main motivations for violence. In these areas, according to the literature, the perception of being humiliated and repressed, the inequalities between men and women, and needs in education and career are prime in motivating female to engage in terrorism. One woman interviewed by Alison stated that she joined the 
LTTE because "Our people have been suffering. The common places and the churches and the Kovils [Hindu temples] were bombed by the government without any reason"

Personal motivations were the second most given motives, cited 18 times. Egotistical motivations include personal problems, many of which have been documented for female terrorists and include being depressed, monetary problems, and the impact of being a social outsider. Personal motivations were noted frequently in publications detailing female's motivations for suicide terrorism.

Idealisitic motivations were the next most common motivations, cited 15 times. Idealistic motivations are similar to social motivations in their altruistic impulse, but reflect more community-based motivations such as a desire for equal rights, an end to social humiliation and repression, and a fight for improved employment and education. The Idealistic motivations discussed in the literature are found across conflict areas, and reflect a female who acts in an effort to change a religious and nationalistic issue in the area. One of the first female Palestinian suicide terrorists, Reem al-Riyashi, arguably expressed her own ideological motivation when she noted "I am committing this act... as an act of revenge against the enemies of humanity who sow destruction in farah, Nablus and the rest of the Palestinian territories... It was always my wish to turn my body into deadly shrapnel against the Zionists." ${ }^{62}$ Such idealistic motivations appeared in a large number of studies examined, although interestingly they are less likely to be found in publications discussing female motivations for suicide terrorism.

Among the other motivations discussed in the literature, many focus more on the person than context and are thus egotistical motivations. It is often suggested that some women are motivated by key events or circumstances that were beyond their 
control. For example, death of a loved one by the oppressor can act as the final straw in the decision to become involved. This was the case with Asja Gasujewa, who along with 15 other family members carried out an attack in Chechnya after the death of her husband. Indeed, key events such as displacement, the loss of a loved one, or humiliation, were cited as motivating influences twelve times. Key events can lead to a desire for revenge, and revenge motivations have also been documented in women. One example of this is Hanadai Jaradat who carried out a suicide attack in Palestine to avenge the death of her fiancée. However, the desire for revenge, possibly resulting from these key events, was the least frequently noted motivation, cited only four times.

\section{Recruitment}

Case study research also reveals a wealth of information regarding the recruitment or pathway to terrorism. While the issue of recruitment is seldom the explicit focus of the female terrorism literature, a number of recruitment pathways are easily identified within case studies. In some instances, females appear to join terrorist groups voluntarily, as suggested by papers that have studied the European left-wing, Sri Lankan and Palestinian terrorist groups ${ }^{63}$. Others appear to join as a result of recruitment drives by the terrorist group. Examples of such drives are seen in the recruitment processes of American racial terrorist groups and Latin American guerrilla groups. As Alison notes, female participation in the LTTE was not widespread in the 1970s but from the 1980s appeals were made for women to join the struggle and women were recruited aggressively ${ }^{64}$.

Alongside these two forms of recruitment, the literature suggests a number of additional influences that persuade females to join a cause. Principle among these are peer pressure and group conformity, which has been documented as occurring in or 
through university networks ${ }^{65}$ and on-line chat rooms and discussion boards ${ }^{66}$. Women have also been influenced by the men that they are close to and often join terrorist organizations alongside or shortly after their boyfriends, partners or lovers. In research on the conflict in Northern Ireland, for example, Alison found that paramilitary women were often introduced to the organization through male family members ${ }^{67}$. Women may also be forced to join extremist groups, as was the case with many of the female LTTE members interviewed by Ness ${ }^{68}$. Across the literature no one form of recruitment is dominant or mentioned significantly more so than any other.

This section and the previous section considered the different reasons and ways in which females become involved in terrorism. The number of motivations and recruitment processes identified within the literature undoubtedly reflects the complexity of the issue at hand. Yet, within the current sample, no publication has examined the interaction of motivation and recruitment and how this can influence female participation in terrorism. A recent study by the current authors ${ }^{69}$ examined the interrelationships among the motivation and recruitment of female terrorists. Using a statistical analysis of data on thirty females, these authors found an interaction effect between motivation and recruitment, which suggests either that different forms of recruitment evoke particular motivations or that extremist groups are sensitive to females motivational vulnerabilities and adapt their method of recruitment accordingly. The study was not able to tease apart the direction of this relationship but it shows that an understanding the relationship may provide further insights into the radicalization process. 
Roles

The literature identifies a number of different roles that females play within terrorist groups. These are summarised in Table 3. In this Table, the dark shaded tickmarks represent roles that women are often cited as having within an extremist organisation. The lighter tick-marks represent roles that women have been identified as playing within an organisation but rarely, with women in these positions often being considered exceptional cases by authors of the research. Our labelling of roles follows those proposed by Griest and Mahon ${ }^{70}$, whose typology considers female involvement in terrorist groups and incorporates traditional female roles (e.g., nurse within a camp). As Griest and Mahon describe, female sympathisers are followers who perform duties such as cooking, cleaning and first aid in extremist camps. In contrast, females are termed Spies when they play a more active role by acting as decoys, messengers or intelligence gatherers. Further up the organisational ladder, females categorised as warriors are those arguably more active again, fighting in battles on an equal status with men. Finally, females at the top of the organisation and actively involved in the leadership, motivation and strategy are dominant forces within that group. Griest and Mahon did not include suicide bombers in their typologies of roles, but this category will be included in the current study due to the high numbers of articles detailing female involvement in suicide terrorism.

The order of extremist groups and roles within Table 3 have been arranged to reflect an important relationship among the roles that females take in extremist groups. Specifically, with the exception of women as suicide bombers, it is possible to arrange the categories and associated tick-marks in such a way as to suggest an ordering to the roles that women take up within terrorist organisations. For example, the literature suggests that women do not occupy the position of dominant forces 
within a group without also being active as warrior leaders. Similarly, women are not active as warrior leaders without also being active as warriors, nor active as warriors without also being active as spies. The various roles that women can hold within a terrorist organisation are ordered in a precise way, from minor roles to more major decision making positions.

This type of cumulative relationship among attributes is known as a Guttman scale, and it has two important properties. The first is that arrangement of attributes in a Guttman scales is deterministic in the sense that a positive response at one level of the scale indicates a positive response at all lower points of the scale. For example, if women are not active as spies and warriors within a particular extremist group, then it is likely that this group will also not employ women as warrior leaders or dominant forces. Women need to have been active at the lower, more common level of spy before they also appear in the organization as a leader. Second, terrorist organisations themselves can be ordered according to their use of women within the group, from those in which women play a minimal role to those in which women occupy a number of different positions.

Figure 3 provides a graphical representation of the Guttman scale of female roles that is implied by the distribution of tick-marks in Table 3 (groups in normal font represent exceptional activity at that level). For example females in European left-wing groups were active at all levels within the group whereas females in al Qaeda are currently used mainly as suicide bombers. While the scaling used in the current study is not exhaustive, the knowledge of the roles played by women in different terrorist organisations may be useful in assessing the threat posed by a group based on exemplar actions. 
Using the two main qualities of the Guttman scale outlined above, it is possible to make some important observations about the roles of females in terrorist organisations. All terrorist groups require community support ${ }^{69}$ and the role of women as sympathisers in all groups suggests that females play a large role in providing such support. From the common use of women as spies we can deduce tactical considerations on behalf of terrorist groups. Women are (still) little expected as information gathers and are often granted increased access compared to men, which is something groups considered when recruiting women ${ }^{71}$. However, it is the use of females in the higher positions that is most revealing of terrorist organisations. The groups included in the current review can be split according to their use of women in more senior roles.

The groups towards the upper rows of Table 3 and Figure 3 are left wing groups fighting for state independence or liberatory nationalism ${ }^{72}$. This concentration on breaking away from state constraints and forming a new community offers women a larger space within which to participate as combatants. The progressive outlook of the group, the potential promise of gender equality and the revolutionary challenging nature of the group holds greater attraction for women in terms of current active participation and a future higher quality of life ${ }^{73}$. Groups located towards the bottom of Table 3 and Figure 3 are characterised by either strict religious or cultural norms, or motivations that do not envisage a change in society itself. Al-Qaeda, Chechen and Palestinian terrorists all promote strict religious or cultural rules governing women's behaviour. This restriction to women's activities in everyday life is mirrored by restricted roles for women within the terrorist groups. Similarly, the Irish Loyalists and International Latin American groups are both right-wing groups that do not wish to change society itself or roles within that society and female roles in these 
organisations mirror female roles in society. These groups offer women only a small space within which to participate as combatants, being unwilling to admit women to roles they do not usually hold in that society, or change the roles that they perform.

The groups in the middle of the diagrams, namely ETA and American rightwing groups, are exceptions to this pattern. Within ETA, women appear to play more traditional, or minor, roles such as spies or sympathisers. This is unusual for a liberatory group as such groups often encourage female participation as a sign of change and social progression Alison ${ }^{74}$. While this is unusual, it is not altogether unexpected. Reinares, for example, argues that this may be due the relatively static proportion of male and female group members throughout recent group history and stricter gender roles within Basque society ${ }^{75}$. In contrast, the right-wing American groups are unusual in their use of women but due to the breadth rather than restricted nature of roles that females occupy ${ }^{76}$. It is difficult to determine whether this pattern may be due to the equal gender roles seen in American society, or simply a need for members, but the results reiterate findings that women are traditionally more active in left-wing groups ${ }^{77}$. They also highlight the role that culture and society play in the definition of women's roles within terrorist organisations as well as in everyday life.

The one exception to the role analysis that we have discussed so far is the use of women as suicide bombers. As can be seen from Table 3, the role of suicide bombing is qualitatively different to that of all the other roles, which are comparable. Thus, the deployment of women in other roles may give little indication of when groups are likely to use women as suicide bombers. This claim is supported by the use of female suicide bombers across a range of ideological groups, from Chechen and Palestinian rebels to the LTTE and Al-Qaeda. This disparate use of women as suicide bombers as opposed to more 'traditional' fighters in Palestine, Chechnya and for al- 
Qaeda has led to claims that the women chosen to become suicide bombers are used as sacrificial lambs ${ }^{78}$ or are coerced into carrying out an attack ${ }^{79}$.

\section{Environmental Enablers}

The right hand column of Table 3 shows that female participation in conflicts grows over time, since all but two conflicts saw an increase in female participation. Alison notes that women joined the LTTE partly in response to the shortage of male combatants as a result of extended conflict ${ }^{80}$. However, there are more factors involved than merely conflict duration. Figure 4 details the different environmental enablers cited in the literature, and the frequency of their mention. The enablers are grouped under four headings of strategy, internal strategy, advantages to group and social conditions. Women offer a number of strategic advantages for the benefit of both terrorist attacks and the terrorist group itself and are cited most frequently.

Women have increased access to $\operatorname{targets}^{81}$, they are incongruent with typical security profiles $^{82}$ and they arise less suspicion ${ }^{83}$. The research indicated that these strategic advantages are especially salient when considering the use of women as suicide bombers (as focused on by nearly half of the sampled publications, as their participation in this type of activity is still considered rare or unusual).

The second most referenced category of environmental enablers is Social Enablers. Victor argues that terrorist groups appear to be willing to use women as terrorists only when public attitude is favourable towards this action ${ }^{84}$. In the absence of favourable social conditions, it is unlikely that women will actively participate in a terrorist group, although they may act as sympathisers. Terrorism has to be seen as legitimate for women and justified under current conditions ${ }^{85}$. The research indicates that national and political developments alongside religious allowances or fatwas can dictate the use of women in such circumstances. For example, a change in religious 
decrees after the first few female Palestinian suicide led to their more frequent use by a broader range of terrorist groups ${ }^{86}$. However, the most favourable social condition for women's inclusion in terrorist groups not in the literature is equality of gender roles in society which can often paves the way for equality of gender roles in terrorism, such as in the radical American right-wing groups. Yet, even with gender equality women need to be willing to join the terrorist organisation, and be committed to the cause if they are to be effective. Nonetheless, research has shown that an advantage and therefore enabler of women's participation is their willingness to become involved and their often deeper commitment to the cause ${ }^{87}$.

Our analysis revealed that women afford several other advantages to a terrorist organisation. They help, for example, attract media attention and may be used and recruited when there is a desire for heightened (inter)national attention ${ }^{88}$. Similarly, women elicit feelings of sympathy for the cause, sending out a message that times are so hard that even women are being sacrificed for the cause ${ }^{89}$. Women terrorists can also improve the terrorist organisation as a whole. Enlisting women provides an efficient use of the population and they have been shown to enhance group stability ${ }^{90}$, increase motivation $^{91}$, and provide an efficient use of the population ${ }^{92}$.

Other

Two articles did not fit within the above categories. The first examines the criminology of terrorism, noting the importance of gender and social implications when analysing a person's activities. It argues that to understand female suicide terrorism it is necessary to focus on both the offender as a person and on the social conditions giving rise to the opportunity to carry out the attack ${ }^{93}$.

The second study focuses on how to try and counter female terrorism ${ }^{94}$. It was the only study to examine security issues surrounding women's involvement in 
terrorism and to explore future potential threats from female terrorists. It identifies six counter-terrorism deficiencies that help explain why observers failed to anticipate the emergence and scope of female militancy. Their understanding, anticipation and response to: exploitation, organisational, technological, denial and deception, tactical and cultural-ideological factors.

\section{Discussion}

In this paper, we summarised 54 academic publications that focused on female involvement in extremism. The papers consider a range of areas, branching across historical analyses of female involvement and the societal context in which this occurred, to ideographic studies focused on the roles, motivations and recruitment of females found to be involved in extremism. In reviewing the papers, we assessed this body of work in terms of the methodological quality of the research and the information found within.

\section{Methodological Quality}

The current analysis has shown a reliance on secondary data and a lack of statistical analysis, similar to the field of general terrorism research a few years ago ${ }^{95}$. The combined issues of a shortage of primary data and few statistical analyses raise questions about the reliability of results and conclusions drawn from such research. It also reveals a lack of growth within the field as studies are not progressing from descriptions of events to the explanations that come with the building and testing of theories. As Silke notes, subject areas that fail to make the transition from description to explanation are left with gaps in their knowledge base and an uncertainty over the true causes and factors at work $^{96}$.

The problem of a lack of primary research is one not easily addressed by researchers in the field. Research into terrorism is difficult and even potentially 
dangerous. Even when within a conflict situation, ideal data collection conditions are unlikely to occur. A large proportion of primary research cited within the literature came from media sources, in particular journalist interviews with terrorists.

In contrast, the lack of statistical analysis with existing and future data can be more easily addressed. Since the 1950 s, a number of methodologies, ideally suited to qualitative data, have been devised or made easier for researchers to employ ${ }^{97}$. Examples include grounded theory and content analysis ${ }^{98}$ for examining interviews and personal accounts (e.g., diaries), log-linear analysis for examining the relationship among categorical or ordinal variables ${ }^{99}$, and sequence analysis methods for examining the life histories of targets ${ }^{100}$. These techniques, devised for qualitative and narrative data such as those found in terrorism research, may be easily applied to (female) terrorism. For example, Jacques and Taylor's (in press) recent study of female terrorism uses grounded theory combined with log-linear modelling to compare and contrast the motivations and recruitment of male and female suicide terrorists. In doing this, multiple case studies and competing hypotheses were been combined and tested statistically. Applications such as this can help move studies of terrorism forward from simple descriptions of cases to explanations of what is seen.

\section{Context}

Overview. Nearly half of the articles in the current sample were an overview of female involvement in specific conflicts or in terrorism as a whole. Such exploration and description is useful in the initial stages of a body of research ${ }^{101}$. However, the study of female terrorism is growing and expanding rapidly. With this increase, the field of female terrorism needs to move from a description of events to an explanation in order to avoid the 'conceptual mire' that has 'bogged down' research on terrorism in general ${ }^{102}$. For this to occur, publications need to move from 
outlining general details to specifics and theories detailing which women become involved, when they get involved, and how they get involved. Without these details the transition cannot be made between levels of understanding and we are left with gaps in the knowledge base and an uncertainty over the causes of events and the significant factors at work ${ }^{103}$.

The peril on continuing to not focus on producing evidence-based knowledge goes beyond a lack of cumulative development in the field. As the studies of perceptions have revealed, studies investigating the perceptions and media reporting of female terrorists have revealed that our reliance on outdated and easily digestible stereotypes are hindering our understanding of female terrorism. As terrorist organisations learn about the use and reliance on reporting stereotypes, there remains the opportunity to exploit the cultural gender clichés employed by the media and used by counter-terrorism agencies ${ }^{104}$. The Western media's focus on personal and situational characteristics of female terrorists also disguises the potentially harder to accept religious and nationalistic motivations reported in the Arab press. Research examining (media) perceptions of female terrorism with the goal of highlighting the risks involved with reporting only one side of the motivational story would significantly benefit security organisations and policies by highlighting bias within reporting, and possible errors in terrorist profiles derived solely form Western sources. An important aspect of exposing the finer details of female involvement includes considering female motivations and recruitment. Within the current research, case studies and interviews with female extremists revealed many differing motivations and recruitment processes. These case studies serve as excellent illustrative pieces, detailing thought processes, aims and actions. Yet, they also contain a wealth of unused information. The data within these articles have been 
described or related, but not combined, compared or contrasted. Yet, this bringing together of data and its analysis across cases is imperative when trying to explain female terrorism. By collating information, examining and evaluating it, hypotheses about motivations and recruitment may be tested and old theories adjusted or new ones built.

The reviewed papers suggest that along with a range of motivations and recruitment procedures women also hold a wide range of roles within terrorist organisations and that there is a progression in the types of roles that women hold within a terrorist organisation. How far women progress along these roles was shown to be partially dependent on the ideology of the group and thus social factors including the context and aim of the conflict should be taken into consideration when trying to predict women's involvement. One exception to this progression was the role of a suicide bomber. A Guttman scale analysis suggested that suicide bombing is a qualitatively different role to that of sympathiser, spy, warrior, or leader (Figure 3). The finding regarding women as suicide bombers shows that this role does not come as a natural progression from other forms of duty and suggests that female suicide bombers are not just fighters, but tactical deployments (willing or not). Whether this is also the case with men has yet to be investigated using similar analyses.

Further investigation is also needed in a number of other areas. For example, only a few of the reviewed papers focused on understanding of conditions under which women partake in terrorism. Yet, an understanding of the conditions under which women partake in terrorism is necessary to predict when women will become involved in a conflict, and it is thus important when devising security and counterterrorism plans. The current literature sample identified only one study examining the specific problems which women may pose for counter-terrorism organisations. Given 
the current increase in the number of female terrorists this is an aspect which has been much neglected within the field. If there are aspects which are unique to female, rather than male terrorism, such as when they become active fighters and how they are deployed within the conflict, then security policies and counter-terrorism plans should incorporate these into their measures.

\section{Conclusion}

Research into female terrorism is growing, encompassing a diverse range of topics such as feminism, motivation and recruitment, women's roles and environmental enablers. However, the majority of research describes rather than explains the phenomenon. There is an over-reliance on secondary data, and data remains dispersed over individual pieces of research preventing more detailed comparative analyses. Future directions for research as indicated by isolated studies within the current sample include analysing the environmental factors enabling female involvement and identifying counter-terrorism measures specifically for females. An understanding of the processes and steps through which women progress as they become more involved in terrorism should help elucidate the motivations and recruitment that underlie their involvement. 
Table 1. Main Focus of Articles on Female Terrorism

\begin{tabular}{|c|c|c|c|}
\hline Article Focus & $\begin{array}{c}\text { Focus } \\
\text { Category }\end{array}$ & $\begin{array}{l}\text { Main } \\
\text { focus }\end{array}$ & $\begin{array}{c}\text { Secondary } \\
\text { Focus }\end{array}$ \\
\hline Overview of female & & & \\
\hline terrorism & Overview and history of female & & \\
\hline $\begin{array}{l}\text { Details of women in } \\
\text { specific conflicts }\end{array}$ & involvement in terrorism & 22 & 7 \\
\hline $\begin{array}{l}\text { Perceptions of } \\
\text { female terrorists }\end{array}$ & Perceptions and media & 11 & 4 \\
\hline $\begin{array}{l}\text { Feminism, female } \\
\text { terrorism and society }\end{array}$ & Feminism and gender studies & 6 & 11 \\
\hline Women's roles & Women's roles & 6 & 14 \\
\hline $\begin{array}{l}\text { Motivation and/or } \\
\text { recruitment }\end{array}$ & Motivation and recruitment & 5 & 30 \\
\hline $\begin{array}{l}\text { Impact of religion on } \\
\text { female involvement }\end{array}$ & Environmental enablers & 3 & 9 \\
\hline Criminology & & & \\
\hline $\begin{array}{l}\text { Countering female } \\
\text { terrorism }\end{array}$ & Other & 1 & 2 \\
\hline
\end{tabular}


Table 2. Female motivations and their frequency within the literature.

\begin{tabular}{|c|c|c|}
\hline Motivation Category & Example Motivations & Frequency of Mentions \\
\hline \multirow{3}{*}{ Social } & Gender equality & \\
\hline & Education/career needs & 34 \\
\hline & Humiliation and repression & \\
\hline \multirow{4}{*}{ Personal } & Family problems & \\
\hline & Personal distress & 18 \\
\hline & Monetary worries & \\
\hline & Social outsider & \\
\hline \multirow{4}{*}{ Idealistic } & Religion & \\
\hline & Nationalism & 15 \\
\hline & Commitment to cause & \\
\hline & Wish for martyrdom & \\
\hline \multirow{4}{*}{ Key Event } & Loss of loved one & \\
\hline & Specific humiliating instances & 12 \\
\hline & Displacement & \\
\hline & Other negative uncontrollable event & \\
\hline \multirow{2}{*}{ Revenge } & Vengeance & \\
\hline & Anger & 4 \\
\hline
\end{tabular}


Table 3. Women's roles in terrorism.

\begin{tabular}{|c|c|c|c|c|c|c|c|}
\hline Group & Sympathisers & Spies & Warriors & $\begin{array}{l}\text { Warrior } \\
\text { Leaders }\end{array}$ & $\begin{array}{c}\text { Dominant } \\
\text { Forces }\end{array}$ & $\begin{array}{l}\text { Suicide } \\
\text { Bombers }\end{array}$ & $\begin{array}{c}\text { Participation } \\
\text { Grown? }\end{array}$ \\
\hline European & $\checkmark$ & $\checkmark$ & $\checkmark$ & $\checkmark$ & $\checkmark$ & & $\checkmark$ \\
\hline \multicolumn{8}{|l|}{ Left-wing } \\
\hline LTTE & $\checkmark$ & $\checkmark$ & $\checkmark$ & $\checkmark$ & $\checkmark$ & $\checkmark$ & $\checkmark$ \\
\hline Domestic & $\checkmark$ & $\checkmark$ & $\checkmark$ & $\checkmark$ & $\checkmark$ & & $\checkmark$ \\
\hline \multicolumn{8}{|l|}{ Latin Am. } \\
\hline IRA & $\checkmark$ & $\checkmark$ & $\checkmark$ & $\checkmark$ & $\checkmark$ & & $\checkmark$ \\
\hline \multicolumn{8}{|l|}{ right-wing } \\
\hline ETA & $\checkmark$ & $\checkmark$ & $\checkmark$ & $\checkmark$ & & & $\checkmark$ \\
\hline Palestinian & $\checkmark$ & $\checkmark$ & & & & $\checkmark$ & $\checkmark$ \\
\hline Chechen & $\checkmark$ & & & & & $\checkmark$ & $\checkmark$ \\
\hline International & $\checkmark$ & & & & & & \\
\hline \multicolumn{8}{|l|}{ Latin Am. } \\
\hline Irish & $\checkmark$ & & & & & & \\
\hline \multicolumn{8}{|l|}{ Loyalists } \\
\hline Al Qaeda & & & & & & $\checkmark$ & $\checkmark$ \\
\hline
\end{tabular}

NOTE: $\checkmark=$ Females are often found in these roles within the group.

$\checkmark=$ Females positioned in these roles are typically exceptional and rare. 
Figure 1. Frequency of publications on female terrorism from the year 1983-2006

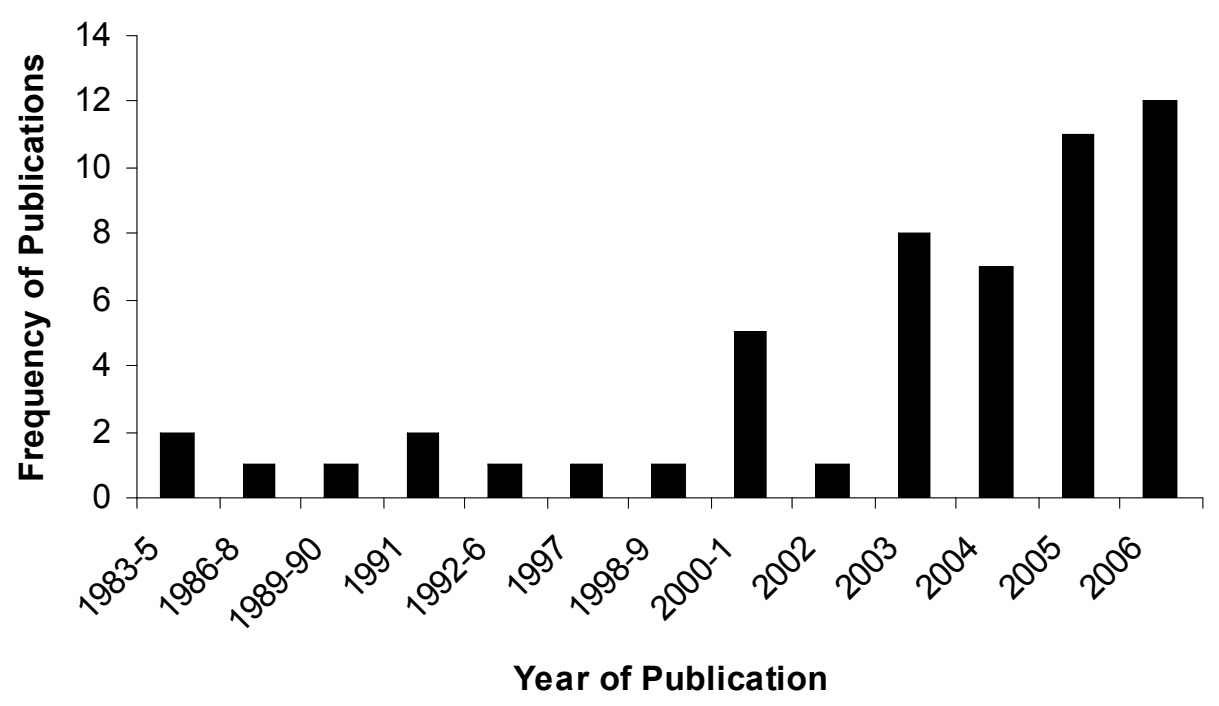


Figure 2. Frequency of studies using statistics.

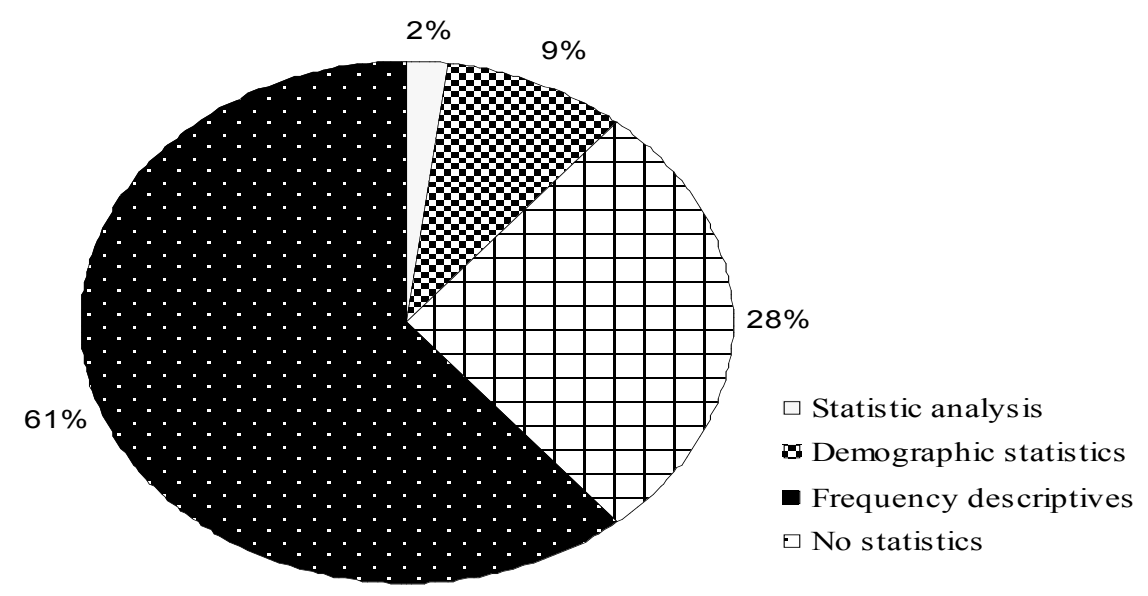


Female Terrorism 35

Figure 3. Guttman scale of female terrorist roles and corresponding groups

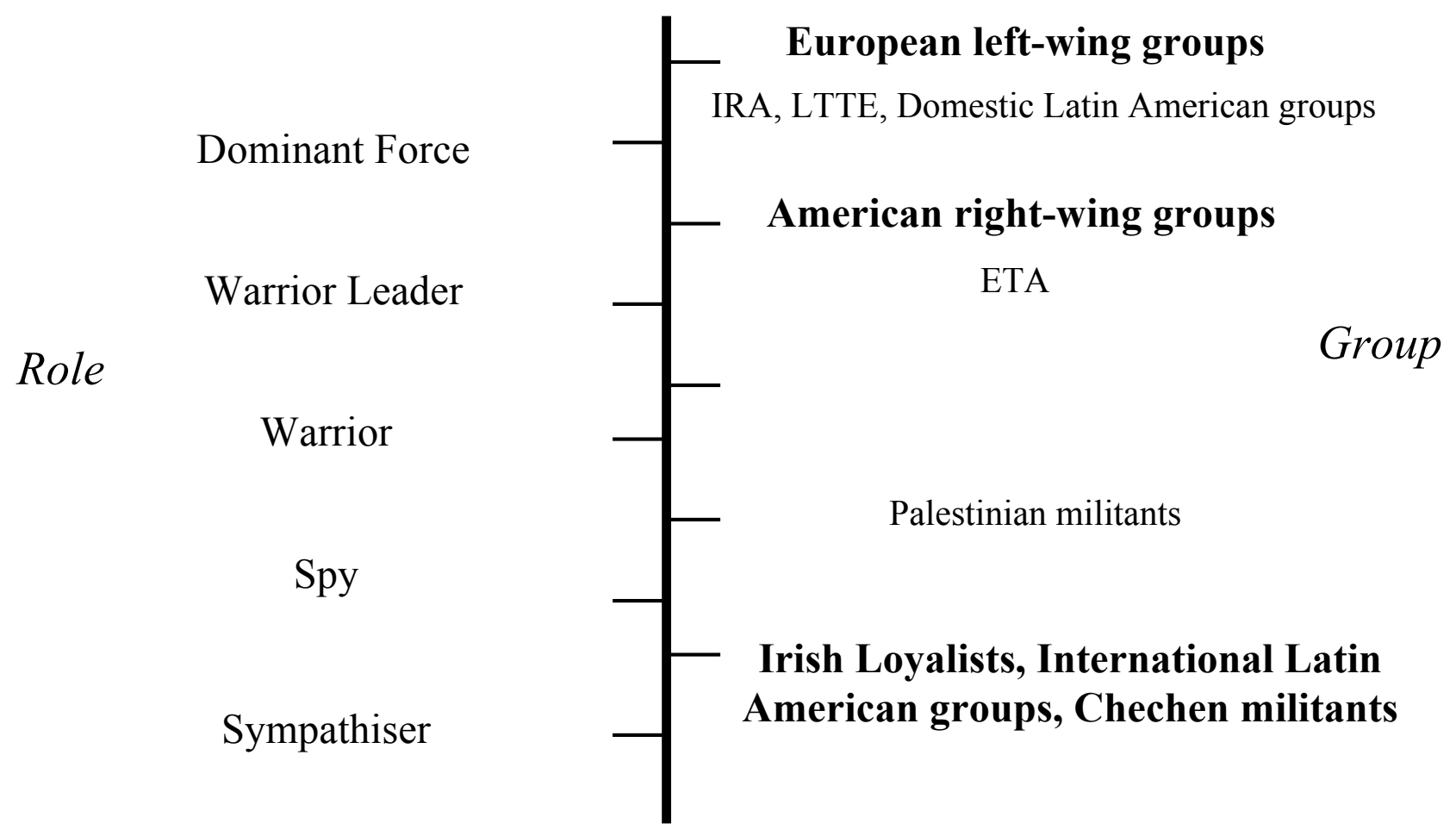

N.B. Groups in bold represent groups in which women are often found in those roles within that group.

Groups in normal font represent those where women's activity at that level has been exceptional 
Figure 4. Environmental enablers of female participation in terrorism.

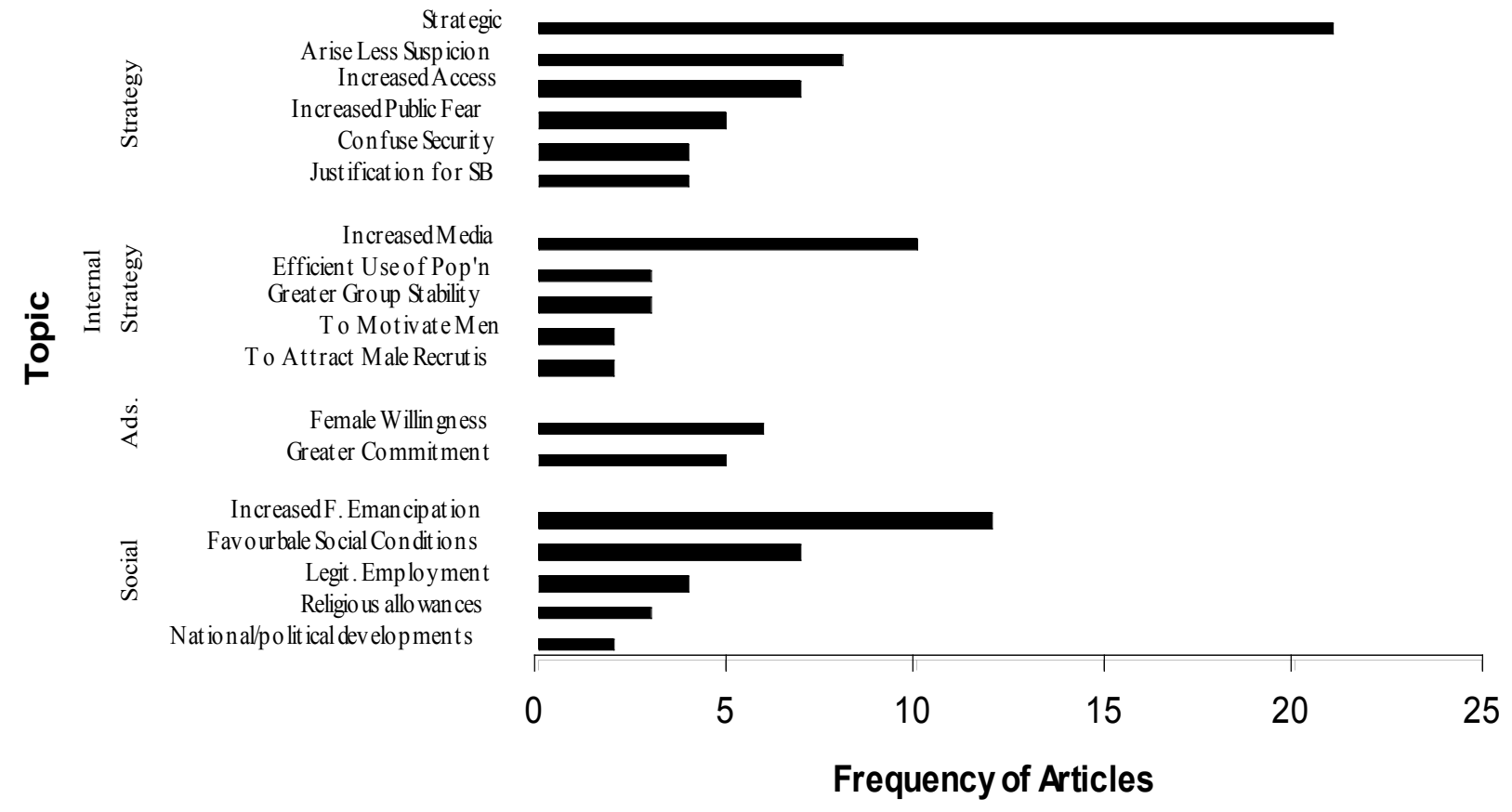


1 Daniel E. Georges-Abyeie, "Women as Terrorists," in Perspectives on Terrorism, ed. Lawrence Zelic Freedman and Yonah Alexander (Wilmington, Delaware:

Scholarly Resources, 1983), PP.

${ }^{2}$ Karla J Cunningham, "Cross-Regional Trends in Female Terrorism," Studies in Conflict \& Terrorism 26, no. ? (2003): PP.

${ }^{3}$ J. Peter Burgess, "Commentary," Security Dialogue 35, no. ? (2005): PP. Cindy D. Ness, "In the Name of the Cause: Women's Work in Secular and Religious Terrorism," Studies in Conflict \& Terrorism 28, no. ? (2005): PP.

${ }^{4}$ Martyn Hammersley, "Qualitative Data Archiving: Some Reflections on Its Prospects and Problems," Sociology 31, no. 1 (1997): PP.

${ }^{5}$ Ibid. Margarete Sandelowski, Sharron Docherty, and Carolyn Emden, "Qualitative Metasynthesis: Issues and Techniques," Research in Nursing \& Health 20, no. ? (1997): PP.

${ }^{6}$ Deborah Zedalis, "Female Suicide Bombers," in Carlisle Papers in Security Strategy (US Army War College, 2004).

${ }^{7}$ Ness (note 3).

${ }^{8}$ Amy Knight, "Female Terrorists in the Russian Socialist Revolutionary Movement," Russian review 38, no. 2 (1979): PP.

${ }^{9}$ Linda L. Reif, "Women in Latin-American Guerrilla Movements - a Comparative Perspective," Comparative Politics 18, no. 2 (1986): PP.

${ }^{10}$ Georges-Abeyie (note 1).

${ }^{11}$ Eileen McDonald, Shoot the Women First (New York, NY: Random House, 1991).

Luisella De Cataldo Neuburger and Tiziana Valentini, Women and Terrorism (London, UK: Macmillan Press Ltd, 1992).

${ }^{12}$ Georges-Abyeie (note 1).

${ }^{13}$ Yoram Schweitzer, "Palestinian Female Suicide Bombers: Reality Vs. Myth," in Female Suicide Bombers: Dying for Equality? (Tel Aviv: Jaffee centre for strategic studies, 2006).

${ }^{14}$ Rhiannon Talbot, "Myths in the Representation of Female Terrorists," JOURNAL, Vol, no. ? (2001): PP.

${ }^{15}$ Andrew Silke, "The Devil You Know: Continuing Problems with Research on Terrorism," Terrorism and Political Violence 13, no. 4 (2001): PP.

${ }^{16}$ Martha Crenshaw, "The Psychology of Terrorism: An Agenda for the 21st Century," Political Psychology 21, no. 2 (2000): PP. McDonald (note 11).

${ }^{17}$ Ami Pedahzur, Arie Perliger, and Leonard Weinberg, "Altruism and Fatalism: The Characteristics of Palestinian Suicide Terrorists," Deviant Behavior: An Interdisciplinary Journal 24 (2003): PP.

${ }^{18}$ David Cook, "Women Fighting in Jihad?," Studies in Conflict \& Terrorism 28 (2005): PP.

${ }^{19}$ Karen Kampwirth, Women \& Guerrilla Movements: Nicaragua, El Salvador, Chiapas, Cuba (Philadelphia, PA: Pennsylvania State University Press, 2002).

${ }^{20}$ Teri Patkin, "Explosive Baggage: Female Palestinian Suicide Bombers and the Rhetoric of Emotion," Women and Language 27, no. 2 (2004): PP.

${ }^{21}$ Maria Alvanou, "Criminological Perspectives on Female Suicide Terrorism," in Female suicide bombers: dying for equality? (Tel Aviv: Jaffe centre for strategic studies, 2006). 
${ }^{22}$ Bridgette L. Nacos, "The Portrayal of Female Terrorists in the Media: Similar Framing Patterns in the News Coverage of Women in Politics and in Terrorism," Studies in Conflict \& Terrorism 28 (2005).

${ }^{23}$ Mira Tzoreff, "The Palestinian Shahida: National Patriotism, Islamic Feminism, or Social Crisis," in Female Suicide Bombers: Dying for Equality? (Tel Aviv: Jaffe centre for strategic studies, 2006).

${ }^{24}$ Kathleen M. Blee, "Women and Organized Racial Terrorism in the United States," Studies in Conflict \& Terrorism, 28 (2005).

${ }^{25}$ Sally Boniece, A, "The Spiridonova Case, 1906: Terror, Myth and Martyrdom," Kritika: Explorations in Russian and Eurasian History 4, no. 3 (2003).

${ }^{26}$ Karen Jacques and Paul J Taylor, "Male and Female Suicide Bombers: Different Sexes, Different Reasons?," Studies in Conflict \& Terrorism (in press).

${ }^{27}$ Silke (note 15).

${ }^{28}$ Frederic Wolf, M, Meta-Analysis: Quantitative Methods for Research Synthesis (Quantitative Applications in the Social Sciences) (London, UK: Sage, 1986).

${ }^{29}$ Mary Dixon-Woods et al., "Integrative Approaches to Qualitative and Quantitative Evidence," (NHS Health Development Agency, 2004).

${ }^{30}$ Nicholas Mays, Edward Roberts, and Jennie Popay, "Synthesising Research Evidence," in Studying the Organization and Delivery of Health Services., ed. N. Fulop, Allen, P., Clarke, A. and Black, N. (London, UK: Routledge, 2001).

${ }^{31}$ Dixon-Woods et al. (note 29).

${ }^{32}$ Louise A Jensen and Marion N Allen, "Meta-Synthesis of Qualitative Findings," Qualitative Health Research 6, no. 4 (1996). Rita Schreiber, Dauna Crooks, and Phyllis Stern, "Qualitative Meta-Analysis," in Completing a Qualitative Project: Details and Dialogue., ed. J.M Morse (Thousand Oaks, CA: Sage, 1997).

${ }^{33}$ Aron Chibba and Sven Ake Hörte, "Supply Chain Performance - a Meta Analysis.," in "One world? One view of Operations Management?", (Como Lake 2003).

${ }^{34}$ Alison Greenaway and Karen Witten, "Meta-Analysing Community Action Projects in Aotearoa New Zealand," Community Development Journal 41, no. 2 (2005).

35 Martin Cole, Francois Bellavance, and Asmaâ Mansour, "Prognosis of Depression in Elderly Community and Primary Care Populations: A Systematic Review and Meta-Analysis," American Journal of Psychiatry 156, no. 8 (1999). Margarete Sandelowski and Julie Barroso, "Toward a Metasynthesis of Qualitative Findings on Motherhood in Hiv-Positive Women," Research in Nursing \& Health 26 (2003). Barbara Paterson et al., "Living with Diabetes as a Transformational Experience," Qualitative Health Research 9, no. 6 (1999).

${ }_{36}$ Margaret Kearney, "Enduring Love: A Grounded Formal Theory of Women's Experience of Domestic Violence," Research in Nursing \& Health 24 (2001).

${ }^{37}$ Silke (note 15).

${ }^{38}$ Alex P. Schmidt and Albert Jongman, Political Terrorism, 2nd ed. (Royal Netherlands Academy of Arts \& Sciences, 1988).

${ }^{39}$ Silke (note 15 ).

${ }^{40}$ Pedahzur et al. (note 17 ).

${ }^{41}$ Jeanne Daly, Allan Kellehear, and Michael Gliksman, The Public Health Researcher: A Methodological Guide (Melboune: OUP, 1997).

42 Barney G. Glaser and Anselm L. Strauss, The Discovery of Grounded Theory: Strategies for Qualitative Research (Chicago: Aldine, 1967). Ole R. Holsti, Content Analysis for the Social Sciences and Humanities (Reading, MA: Addison-Wesleym, 
1969). Klaus Krippendorff, Content Analysis: An Introduction to Its Methodology (Beverly Hills, CA: Sage, 1980).

43 Anselm L. Strauss and Juliet Corbin, Basics of Qualitative Research: Techniques and Procedures for Developing Grounded Theory (London, UK: Sage, 1998).

Kearney (note 36).

${ }^{44} \mathrm{We}$ also attempted to identify the third foci of papers, but found that the number of papers that could be assigned a third focus reduced significantly compared to the first and second foci analysis. The counts dropped too low to make an analysis meaningful.

45 Jayne Steel, "Vampira: Representations of the Irish Female Terrorist," Irish Studies Review 6, no. 3 (1998). Dan Berkowitz, "Suicide Bombers as Women Warriors:

Making News through Mythical Archetypes," Journalism and Mass Communication

Quarterly 82, no. 3 (2005).

${ }^{46} \mathrm{Nacos}$ (note 22).

${ }^{47}$ Berkowitz (note 44).

${ }^{48}$ Clare Bielby, "'Bonnie Und Kleid": Female Terrorists and the Hysterical Feminine," Forum 1 (2002).

${ }^{49}$ Patkin (note 20).

${ }^{50} \mathrm{Nacos}$ (note 22).

${ }^{51}$ Talbot (note 14).

${ }^{52}$ Ibid.

${ }^{53}$ Claudia Brunner, "Female Suicide Bombers - Male Suicide Bombing? Looking for Gender in Reporting Teh Suicide Bombings of the Israeli-Palestinian Conflict,"

Global Security 19, no. 1 (2005). Avi Issacharoff, "The Palestinian and Israeli Media on Female Suicide Terrorists," in Female Suicide Bombers: Dying for Equality? (Tel Aviv: Jaffee centre for strategic studies, 2006).

${ }^{54}$ Issacharoff (note 52).

${ }^{55}$ Anat Berko and Edna Erez, "Women in Terrorism: A Palestinian Feminist Revolution or Gender Oppresion?," (ICT, 2006).

${ }^{56}$ Robin Morgan, The Demon Lover (New York, NY: W. W. Norton, 1989).

${ }^{56}$ Miranda Alison, "Women as Agents of Political Violence: Gendering Security," Security Dialogue 35, no. 4 (2004). Caron Gentry, "The Relationship between New Social Movement Theory and Terrorism Studies: The Role of Leadership, Membership, Ideology and Gender," Terrorism and Political Violence 16, no. 2 (2004). Jessica West, "Feminist Ir and the Case of the 'Black Widows': Reproducing Gendered Divisions," Innovations: A Journal of Politics 5 (2004).

${ }^{58}$ Gentry (note 56).

${ }^{59}$ Alison (note 56).

${ }^{60}$ McDonald (note 11).

${ }^{61}$ Miranda Alison, "Cogs in the Wheel? Women in the Liberation Tigers of Tamil Eelam," Civil Wars 6, no. 4 (2003).

${ }^{62} \mathrm{http} / /$ www.middleeast.org/forum /fb-public/1/2295.shtml

${ }^{63}$ Neuburger \& Valentini (note 11). Alison (note 63). Clara Beyler, "Messengers of Death -Female Suicide Bombers," (ICT, 2003).

${ }^{64}$ Alison (note 56).

${ }^{65}$ Kampwirth (note 19).

${ }^{66}$ Karla J. Cunningham, "Countering Female Terrorism," Studies in Conflict \& Terrorism 30 (2007).

${ }^{67}$ Alison (note 56). 
${ }^{68}$ Ness (note 3 ).

${ }^{69}$ Jacques \& Taylor (note 26).

${ }^{70}$ Pamela. L Griest and Susan Mahon, "Women as Terrorists," in Terrorism in

Perspective, ed. P. L Griest and S Mahon (London, UK: Sage, 2003).

${ }^{71}$ Rosemary Skaine, Female Suicide Bombers (Jefferson, NC: McFarland, 2006).

${ }^{72}$ For a definition of liberatory nationalism see Alison (note 56).

${ }^{73}$ Margaret Gonzalez-Perez, "Guerrilleras in Latin America: Domestic and International Roles," Journal of Peace Research 43, no. 3 (2006).

${ }^{74}$ Alison (note 56).

${ }^{75}$ Fernando Reinares, "Who Are the Terrorists? Analyzing Changes in Sociological Profile among Members of Eta," Studies in Conflict \& Terrorism 27 (2004).

${ }^{76}$ Blee (note 24$)$.

${ }^{77}$ Cunningham (note 2).

78 Schweitzer (note 13). Barbara Victor, Army of Roses (London, UK: Robinson, 2004).

${ }^{79}$ Ness (note 3 ).

${ }^{80}$ Alison (note 63).

${ }^{81}$ Zedalis (note 6).

${ }^{82}$ Adam Dolnik, "Critical Commentary on "Who Are the Palestinian Suicide Bombers?'," Terrorism and Political Violence 16, no. 4 (2004).

${ }^{83}$ Schweitzer (note 13).

${ }^{84}$ Victor (note 81 ).

${ }^{85}$ Ibid.

${ }^{86}$ Israeli (note 60).

${ }^{87}$ McDonald (note 11).

${ }^{88}$ Zedalis (note 6).

${ }^{89}$ Brunner (note 52).

${ }^{90}$ Blee (note 24).

${ }^{91}$ Berko \& Erez (note 54).

${ }^{92}$ Ness (note 3 ).

${ }^{93}$ Alvanou (note 21).

${ }^{94}$ Cunningham (note 67).

${ }^{95}$ Silke (note 15).

${ }^{96}$ Ibid.

${ }^{97}$ Ibid.

${ }^{98}$ Glaser \& Strauss (note 42 ).

99 Jacques \& Taylor (note 26).

100 Ibid.

${ }^{101}$ Silke (note 15 ).

102 Ibid.

${ }^{103}$ Ibid.

${ }^{104}$ Ibid. 